\title{
Relationship of the Industrial Assessment Center to the Land-Grant Mission of the Oklahoma State University
}

\section{Dr. Hitesh D. Vora, Oklahoma State University}

Dr. Hitesh D. Vora is an Assistant Professor in Mechanical Engineering Technology. He received his Ph.D. and Masters' from the University of North Texas in Materials Science \& Engineering (in 2013) and Mechanical Engineering Technology (in 2008), respectively. Dr. Vora is a Director of the Industrial Assessment Center (IAC) at Oklahoma State University, which is funded by the US Department of Energy (DOE) for the year 2016-2021 with total funding of \$1.8 million. For those not familiar, the Industrial Assessment Centers help small and medium-sized U.S. manufacturers to save energy, improve productivity, and reduce waste by providing no-cost technical assessments conducted by university-based teams of engineering students and faculty. He is actively teaching several courses and pursuing research in advanced (smart/cyber) manufacturing and energy management to improve energy efficiency (reduced energy, cost, and throughput) for small to medium-sized manufacturers.

In addition, he is a Matrixed Professor in the ENDEAVOR Digital Manufacturing Maker Space located in the new ENDEAVOR building, which is a 72,000-square-foot and $\$ 30$ million building. This maker space provides additive manufacturing support for design courses, laboratory courses, and entrepreneur initiatives. This facility houses several different technology 3D printers that capable of printing parts from polymers, fibers, composites, and metals as well as 3D scanning and subtractive manufacturing equipment. His research focuses on machining and manufacturing with a specific concentration on the use of additive manufacturing processes for advanced materials. He emphasis on design for additive manufacturing (DfAM), topology optimization, lightweight applications, and finite element analysis in additive manufacturing processes. Dr. Vora extensively teaches the additive manufacturing technology through the dedicated undergraduate (MET 4173) class as well as through the hands-on training sessions and certification (level 1 to 4) in the Endeavor Digital Manufacturing Maker Space.

\section{Ms. Pragya Niraula, Oklahoma State University}

Pragya Niraula is a graduate student in Industrial Engineering and Management at Oklahoma State University (OSU). She earned a MS degree in Energy Engineering at Asian Institute of Technology, Thailand in 2016 and BS degree in Mechanical Engineering at Tribhuwan University, Nepal in 2010. She has been associated with OSU Industrial Assessment Center since 2017 and has participated in 25 energy assessment in industrial manufacturers. Her area of interest includes energy management, continuous improvement, maximizing energy efficiency and performance in industrial systems.

\section{Amrit Sunil Chugani,}

Amrit Chugani is an undergraduate student at Oklahoma State University pursuing a bachelor's degree in Industrial Engineering \& Management. He is the Vice President of the Institute of Industrial and Systems Engineers organization at OSU and is the Philanthropy Chair at the Beta Nu Chapter of Omega Delta Phi fraternity. He is a dynamic individual who aims to make a positive impact on the world by building successful technology products. His interests include supply chain management, product management, strategy consulting and data analytics.

\section{Mr. Nilesh Anil Baraskar, Oklahoma State University}

Nilesh Baraskar is a graduate student pursuing his master's degree (M.S.) in Industrial Engineering and Management at Oklahoma State University since 2019. He completed his under-graduation (B.E.) in Mechanical Engineering from Savitribai Phule Pune University, India. He is currently working with the Industrial Assessment Center (OSU IAC) as a Graduate Research Assistant under Dr. Hitesh Vora. His areas of interest lie in process improvement, energy management, and supply chain logistics.

Anusha Sunil Saraf, Oklahoma State University 
Anusha Saraf is an undergraduate student pursuing a B.S. degree in Mechanical and Aerospace Engineering at Oklahoma State University. She has been associated with the OSU Industrial Assessment Center since 2019. Her areas of interest include manufacturing, energy systems, and renewable energy.

\section{Dr. Michael L McCombs, Oklahoma State University}

Dr. Michael L. McCombs

Dr. McCombs is Associate Professor of Professional Practice in the Division of Engineering Technology at Oklahoma State University (OSU). He earned a PhD in technical rhetoric at OSU in 2018 and an MA degree in technical writing at Minnesota State University in 2005. Dr. McCombs is the assistant director of the OSU Industrial Assessment Center (IAC), where he has worked in various positions since 2008. He has particular interest in lighting, HVAC, and M\&V systems, and has participated in nearly 150 IAC assessments of manufacturing plants in Oklahoma, Arkansas, Texas, and Kansas. 


\title{
Relationship of the Industrial Assessment Center to the Land-Grant Mission of the Oklahoma State University
}

\begin{abstract}
The US Department of Energy (DOE)-funded Industrial Assessment Centers (IACs) help U.S. small-and-medium manufacturers to save energy, improve productivity, and reduce waste by providing no-cost energy audits conducted by university-based interdisciplinary teams of engineering students and faculty. The current IAC program at Oklahoma State University (OSU) is funded by DOE for the fiscal years of 2017 to 2021. Overall, there are 31 IACs in the United States, and the OSU IAC serves manufacturers in Oklahoma, Kansas, Arkansas, and North Texas. The OSU IAC program is fully supportive of the land-grant mission of OSU. This program integrates the three important objectives: (i) community service, (ii) teaching, and (iii) research of the land-grant mission. The IAC provides the public service of industrial energy audits at no cost to the client to help reduce energy and waste and to increase productivity, at the same time training students to make them capable of becoming the next generation of energy, sustainability, and productivity professionals. In addition, the IAC works with utilities, manufacturing extension programs, and manufacturing associations to educate them about plant energy conservation and energy management systems. Finally, the IAC team, in the course of its many contacts with manufacturers, learns what practices and products work and which ones don't. Team members share this "field research on the go" with other manufacturers as a form of consumer protection for industry. Land Grant universities have long been serving the needs of small farmers and agribusiness with research, guidance, and training programs, but far-seeing Senator Morrill also had the needs of industry in mind when he pushed the original Morrill Act through Congress in 1862. The national IAC program deserves recognition for its key role in fulfilling the mechanical side of Morrill's original vision for universities that serve the general population rather than only the social elite.
\end{abstract}

Keywords: Industrial Assessment Center, Land-Grant Mission, Energy Assessments, Energy Audits, Service learning 


\section{Introduction}

\subsection{Industrial assessment centers}

Industrial Assessment Centers (IACs) were created by the Department of Commerce in 1976 in response to the Arab Oil Embargo and rising energy costs [1]. The program is provided at no charge exclusive to small and medium-sized manufacturing facilities to cut back on unnecessary costs from inefficient energy use through energy assessment. Large manufacturers are expected to fund themselves for such energy cutting measures and are excluded from the program. Historically, the program originally began in 1976 with four university programs, then called Energy Analysis and Diagnostic Centers (EADC) [2]. The IAC program moved to the U.S. Department of Energy (DOE) and has been in operation since 1978. The IAC program comprises a network of university-based centers that provides opportunities to improve energy efficiency, evaluations of ineffective production procedures, minimize waste production, and other production-related problems in small and medium-sized manufacturers. More recent additions to the IAC program scope also includes improving cybersecurity awareness, exploring smart manufacturing technologies, and implementing comprehensive energy management systems [1].

As of 2020, there are 31 IACs in the United States (Figure 1) and this IAC program has achieved over $\$ 4.5$ billion of implemented energy cost savings since its inception.

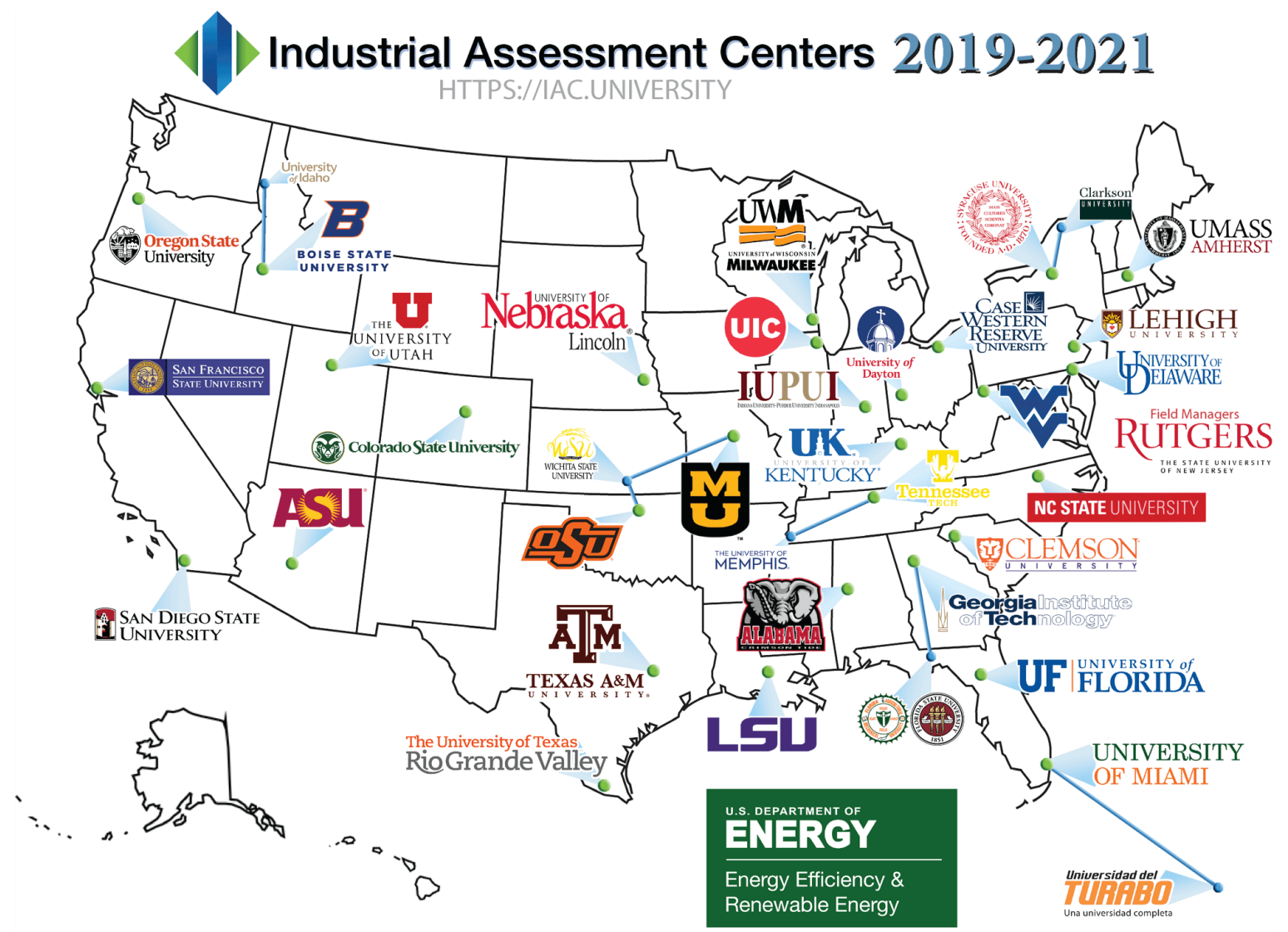

Figure 1: National presence of all 31 IACs. 
Among all 31 IACs in the United States, OSU IAC is home to one of the oldest and most successful industrial energy-efficiency offices in the nation. The OSU IAC has been continuously operational since 1982 [3]. OSU IAC have an affiliation with Wichita State University (WSU) as a Satellite Center (SC). IAC at Oklahoma State University coordinates with its Satellite Center at Wichita State University for conducting approximately twenty-two assessments in small and mid-sized manufacturers from the state of Oklahoma, Kansas, Arkansas, and North Texas as shown in Figure 2 below. Since 1982, the OSU Industrial Assessment Center has helped manufacturers save energy, reduce costs, and increase productivity during an era of energy supply volatility and rising prices.

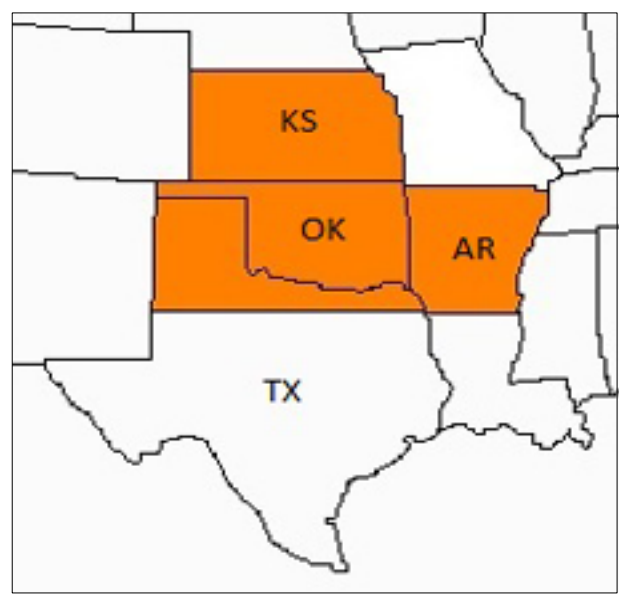

Figure 2: Service territory of OSU IAC in affiliation with its Satellite Center

The stated mission of the OSU IAC is to provide clients, potential clients, and partners with industrial assessments at no cost that will help reduce energy and waste and increase productivity, while educating and training the next generation of energy, waste, and productivity professionals. The goal is to save at least $10 \%$ of client's energy costs, in a cost-effective manner. Over the past five years, the OSU IAC has averaged recommended savings of over $\$ 110,000$ per client (over $14 \%$ of total utility bills), as well as significant savings in $\mathrm{CO}_{2}$ and pollutants in the energy chain. Along with the mission, an associated goal of this organization to produce graduates who are technically competent and able to handle all facets of client relations and communications, so that they will be prepared to serve as energy engineers and to be in demand by employers. Particularly, in the year 2018, the OSU IAC was the first IAC office to reach the $1000^{\text {th }}$ assessment milestone among the 31 IACs nationwide. Moreover, since 1982 the OSU IAC program has contributed $\$ 317$ million or 31.19 Tbtu of implemented energy cost savings and has obtained the reduction of $\mathrm{CO}_{2}$ emissions of 1.91 million metric tons [1].

All of the IAC offices in the nation operate under a consistent set of regulations, performance metrics, and procedures. Nevertheless, there are some differences among the various IACs. Some of them were established decades ago, such as the University of Dayton's IAC (dating from 1981), while others are much newer, such as the Case Western Reserve University IAC (which commenced operation this year). Also, the operation of an IAC is impacted by the primary industrial profile of the region that it serves. For example, the service territory of the San Francisco State University IAC is dominated by high-technology manufacturing in the 
nearby Silicon Valley, whereas much of the client base for the Oklahoma State IAC serves the oil and natural gas industries with a wide range of products to support exploration, drilling, production, transport, and refining of hydrocarbon fuels. Thus, the type of manufacturing equipment encountered on a typical assessment will vary by region. For example, the University of Texas Rio Grande Valley IAC is located in a major vegetable farming area, so the students at this IAC should be very familiar with food processing and packaging equipment. In contrast, students at the University of Delaware IAC must visit many chemical and petro-chemical plants, so they should be conversant with all aspects of boiler operation and combustion optimization.

There are several other entities in the USA that perform industrial energy audits. They include: (1) utility company energy-efficiency incentive program employees; (2) energy conservation consulting firms; (3) energy service performance contractors; (4) professional engineering firms; and (5) salespersons working for original equipment manufacturers and contractors. One might think that with all of these options, there would be no need for the national IAC program, but after the first Arab Oil Embargo in 1973, some members of Congress thought about the need to reduce overall per-capita energy consumption in the USA. And, after the 1979 Iranian Oil Embargo, the federal government passed enabling legislation to create the IAC program to help American industry improve its energy efficiency and reduce national dependence on imported crude oil. There are two key differences that distinguish the IAC program from most of the audit providers listed above:

(A) Half of the mission of the IAC program is to train a new generation of energy engineers, whereas training new engineers is not a priority among the five entities listed above.

(B) Some of the service providers listed above operate under commission selling pressure and other organizational influences that could compromise their objectivity in evaluating an industrial plant's equipment and energy usage.

In contrast, complete objectivity has always been a hallmark of the IAC energy audit service, and this provides a form of consumer protection that was lacking in the industrial market before the development of the IAC program. For decades, energy engineers have witnessed a plethora of inflated savings claims blighting the marketplace, as vendors and contractors have tried to capitalize on utility customers' concerns about rising energy costs. For decades, the Federal Trade Commission (FTC) and other regulators have tried to detect and suppress inflated savings claims resulting from installing energy-saving devices. In one example of many, the FTC warned Newpro (a window manufacturer) that "Any claim about the efficiency, energy savings, fuel consumption, operation cost, cost recovery, or "payback" of an energy-saving product must be truthful and backed up by competent and reliable scientific evidence before you make the claim"[18]. The IAC program is a major source of reliable, objective, and scientifically based advice for decision-makers in industry, when it comes to evaluating potential energy-saving capital investments.

\subsection{Oklahoma State University}

Originally named Oklahoma Agricultural and Mechanical College, Oklahoma State University was founded in 1890 under the Morrill Act, which called for the creation of land-grant universities across the nation. A land-grant university formed under the auspices of the Morrill Acts of 1862 and 1890, this institution has always strived to further the three-pronged land-grant 
mission namely instruction, research and extension [4]. OSU continues to serve as an epitome of a premier land grant university by living and thriving by its values of education and economic growth.

The history of Oklahoma State University (formerly Oklahoma A\&M College) is a journey which officially began in Guthrie on Christmas Eve 1890 in the McKennon Opera House when Territorial Governor George W. Steele signed legislation providing for the establishment of an agricultural and mechanical college as well as an agricultural experiment station in Payne County, Oklahoma Territory, effective December 25, 1890 [5]. At long last, Stillwater was designated as the location for the college by the designated commission. On May 15, 1957, Oklahoma A\&M changed its name Oklahoma State University of Agricultural and Applied Sciences to reflect the broadening scope of curriculum offered. However, the name was quickly shortened to Oklahoma State University for most purposes, and the "Agricultural \& Applied Sciences" name was formally dropped in 1980.

\subsection{Land grant universities}

A land grant university is an academic institution that is funded by the benefits of the Morrill Acts of 1862 and 1860. The Morrill Act of 1862 was passed in response to the industrial revolution, to aid state universities to add mechanical and agricultural colleges to their system with an effort to increase economic growth within that state. Every state had selected one university within its boundaries to receive the land grant status. As the US economy grew, so did the demand for skills in science, engineering and research which ultimately transformed the previous agricultural colleges to large public universities that provide a full spectrum of educational opportunities. Land grant universities have become the foremost public institutions of higher education and scientific research [6].

In the early to mid-1800s, only the elite could afford an advanced education, but all of that began to change in 1857 because of the Morrill Act. Morrill introduced the 'College Land Bill' to Congress, which eventually became the Morrill Act of 1862. The Morrill Act is officially titled as "An Act Donating Public Lands to the Several States and Territories which may provide Colleges for the Benefit of Agriculture and the Mechanic Arts" [7]. A land grant university is such an academic institution that is funded by the benefits of the Morrill Acts of 1862 and 1890: "The mission of the land grant institutions as set forth in the 1862 Morrill Act is to focus on the teaching of practical agriculture, science, military science, and engineering as a response to the industrial revolution and changing social class"[4]. Thus, building on its land-grant heritage, Oklahoma State University promotes learning, advances knowledge, enriches lives, and stimulates economic development through teaching, research, extension, outreach and creative activities. This three-part mission of "teaching, research, and service" was renamed to "learning, discovery, and engagement" as this is what's needed in the evolving $21^{\text {st }}$ century. The overall contribution of the land grant universities to the economic growth of the US was significant as it led to the its rise over UK in terms of growth and power. Oklahoma State University is a modern land grant university as it prepares its students for success through leadership and service and improves the lives of people in Oklahoma, the nation and the world.

OSU has standardized 3 pillars to achieve this mission; they are Instruction, Research and Extension [4]. The university thereby provides high quality education in a variety of different 
majors using the latest teaching methods. Oklahoma State research is in lockstep with its landgrant legacy. OSU research has proved its worth in various aspects whether exploring basic scientific questions or applied concepts that directly impact lives. The university is creating the next generation of scientists, thinkers and scholars through its tradition of research excellence. With the goal of improving the lives of Oklahomans, The Oklahoma Cooperative Extension Service offers a variety of educational programs in extension topics like agriculture, Business finance and marketing, Crops, Community and rural development, fire training etc. It adheres to its commitment by providing educational opportunities to the citizens of Oklahoma.

\subsection{Objective of this article}

The Industrial Assessment Center is an integral part of Oklahoma State University and plays an important role in developing the energy engineers to benefit the community. Its values and mission align with that of the university as it is an epitome of the benefits of the Morrill LandGrant Acts of 1862 and 1890. This paper is an overall review of how the Industrial Assessment

Center at Oklahoma State University aligns with the traditional values of a Land Grant university by participating in its cause and upholding its mission.

\section{Project prospectus}

\subsection{The journey of OSU IAC from 1982 until now and the role of the US DOE}

The OSU IAC program is fully supportive of the land-grant mission of OSU. This program integrates the three important objectives: community service, teaching, and research of the Land Grant mission. The IAC provides the public service of industrial energy audits at no cost to help reduce energy and waste and to increase productivity, at the same time training students to make them capable of becoming the next generation of energy, sustainability, and productivity professionals. In addition, the IAC works with utilities, manufacturing extension programs, and manufacturing associations to educate them about plant energy conservation and energy management systems.

The OSU IAC is home to one of the oldest and most successful industrial energy-efficiency offices in the nation. Particularly, the OSU IAC is the first program to reach the 1000th assessment milestone among the 31 IACs nationwide [8]. This service-and-training project has been consecutively funded by the US Department of Energy every five years since 1982 .

The program pays for itself, and it is not a burden on the taxpayer. The program offers a valuable service to industry at no direct cost to participants. When a company implements projects recommended by an assessment, operating costs are reduced. That cost reduction results in increased taxable revenue (i.e., profits). The tax generated by the increased profits, even accounting for the program's implementation rate, is greater than the DOE program funding. How many other government-funded programs fund themselves? In addition to providing a valuable service to industry that lowers plant operating costs, the program also improves energy education, and trains engineering students [9]. 


\subsection{How the OSU IAC works}

IAC work tasks can be divided into five main categories: (i) Management activities, (ii) Preassessment activities, (iii) On-site assessment activities, (iv) Post-assessment activities, and (v) Implementation activities. The detailed tasks of each activity are explained below:

\section{(i) Management activities}

- Identify potential clients for scheduling assessment

- Contact client, collect plant data to check its eligibility for assessment

- Set up assessment date if client meets eligibility criteria

- Organize team meeting for pre-preparation

- Assign lead author for the assessment report

(ii) Pre-assessment activities

- Create client file, check utility billings for completion

- Contact client, confirm assessment visit date, record pre-assessment survey form

- Do the billing analysis

- $\quad$ Prepare pre audit report

- Program data loggers, charge assessment equipment

\section{(iii) During assessment activities}

- Deliver assessment kick-off meeting

- Collect general information about plant operation, production process

- Conduct plan tour

- Develop action plan to team members

- Collect detailed field data on industrial process equipment

- Develop recommendations based on careful observations

- Deliver closing remarks on possible saving opportunities

\section{(iv) Post assessment activities}

- Store all field data and work on post assessment report

- Assign specific assessment recommendation to team members

- Compile assessment report and send it for review

- Mark corrections and upload final report to Field Manager's database

- Respond and correct to Field Manager's critiques on report

- Mail electronic and hard copies of final report to the client

- Report example can be found from this reference [19]

\section{(v) Implementation activities}

- Email client regarding call back availability

- Mail electronic copy of report to the client

- Ask them about the implementation status of each assessment recommendation provided

- Update the implementation status to Field Manager's database

- Set up a meeting with a team and report its implementation status

IAC OSU is the main center, and WSU is its satellite center. Both centers are mandated to complete 22 assessments per year among which the main center (OSU) conducts 15 assessments, 
and the satellite center (WSU) conducts 7 assessments. The process of conducting an energy audit requires the involvement of all the IAC team in a value chain. One energy assessment procedure normally starts from selecting clients to preparing implementation reports, which lasts approximately for a year. Figure 3 below describes the entire industrial energy audit process, which is categorically described in section 2.2 above.
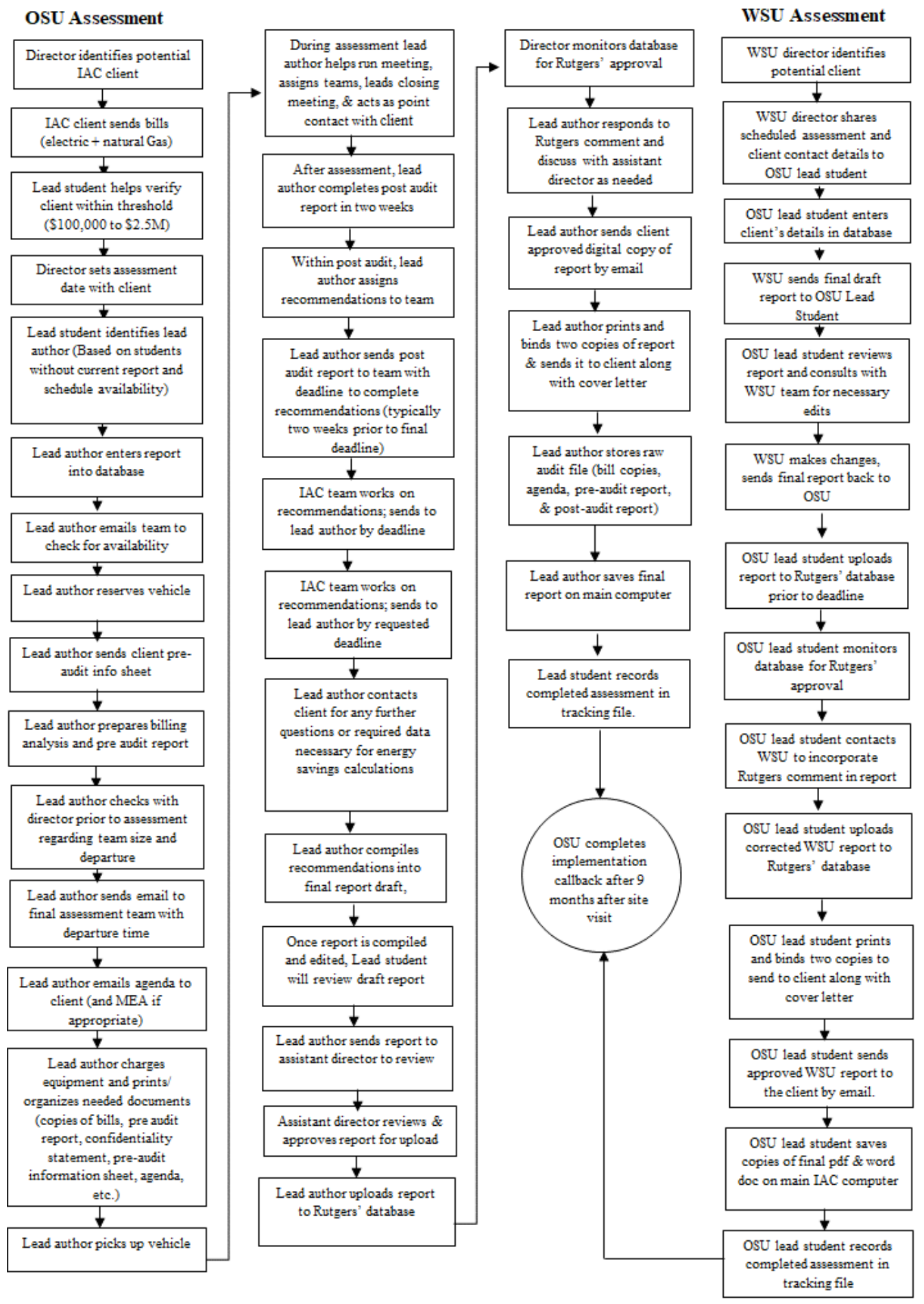

Figure 3: Industrial energy audit process description. 
The energy-saving recommendations in each report are supported by thermodynamic, combustion, electrical, mechanical, and photometric calculations that have long been established by authorities such as ASME, ASHRAE, IEEE, IESNA, NEMA, NIST, and the US Department of Energy. Please see Appendix A for a sample of a typical IAC energy audit report.

The OSU IAC supports the land grant mission by serving a high-quality energy management service to manufacturers across all sectors like aerospace, automobile, oil \& gas, medical, food processing, feed mills etc. To satisfy the needs and the knowledge to carry out these energy audits in different sectors, the OSU IAC hires students from many disciplines, such as Industrial Engineering and Management, Mechanical and Aerospace Engineering, Mechanical Engineering Technology, and more. It also hires undergraduate, graduate, and postgraduate students. The students are trained through a combination of classroom work, mentoring on an individual basis, and firsthand on-the-job training.

The benefits IAC program provides to students are listed below [10]:

- Hands-on training in diagnostics, data collection, and analysis of energy savings opportunities,

- Opportunities to conduct research and author publications related to technical needs and challenges of industry clients,

- Exposure to a wide range of industries, energy systems and solutions,

- Interactions with plant staff, utility representatives and equipment vendors,

- Direct experience implementing U.S., state and local energy policies,

- Work in a consulting-office structure/environment, while completing undergraduate and graduate engineering degrees,

- Expedited ability to obtain professional licensure and certification,

- Experience high demand by recruiters from industry, consulting organizations, utilities, and ESCOs

The OSU IAC provides energy training to 5-10 students each year through on-site energy assessment and by incorporating academic curriculum IEM/MET 5953/4953 which is focused on energy systems. The objective of IEM/MET 5953/4953 is to introduce students to industrial assessments, primarily energy, quality, and productivity-management related, with the objective of improving energy intensity and ultimately bottom-line performance.

The US Department of Energy issues Certificates of Participation to those students who meet the following four criteria:

(i) Have completed two semesters or summers with the IAC

(ii) Have completed minimum of six energy assessment

(iii) Established the minimum of eight core skills among the following skills:

○ Assessment recommendation identification

○ Report writing

- Energy savings calculations

- Client interaction

- Utility data analysis 
- Conceptual assessment recommendation designs

$\circ$ Leadership

- Understanding of ISO 500001 Energy Management Systems

(iv) Completed accurate record in IAC student registry

With the above-listed competency and skills that the student acquires, DOE's initiative of keeping energy conservation and workforce development objectives are achieved in addition to supporting land grant mission of the university. Students identifies areas of improvement in the plant and provide energy saving recommendations which could reduce annual energy utility bills of Oklahoma and its surrounding state's manufacturers by at least $10 \%$.

\subsection{How to measure success}

Figure 4 and 5 outlines the benefits of IAC program for industries, students, faculties and federal government. The efficacy of IAC is measured by four criteria: manufacturer's benefit, student development, environmental benefits, and compliance with the Department of Energy's requirements. IAC program has been useful in highlighting awareness of energy management issues among industrial manufacturers. IAC team brings new energy efficiency technology and procedures to the attention of management that results in informed decision making. Manufacturer's benefits include but not limited to fostering awareness of energy inefficiency, identify ways to lower energy related cost, providing profitable recommendations by quantifying savings, assist in decision making role to install energy efficient equipment. Student development includes training in energy management, utilizing good teamwork and communication skills, unique opportunity of getting hands-on experience of manufacturing operations and its efficient utilization.

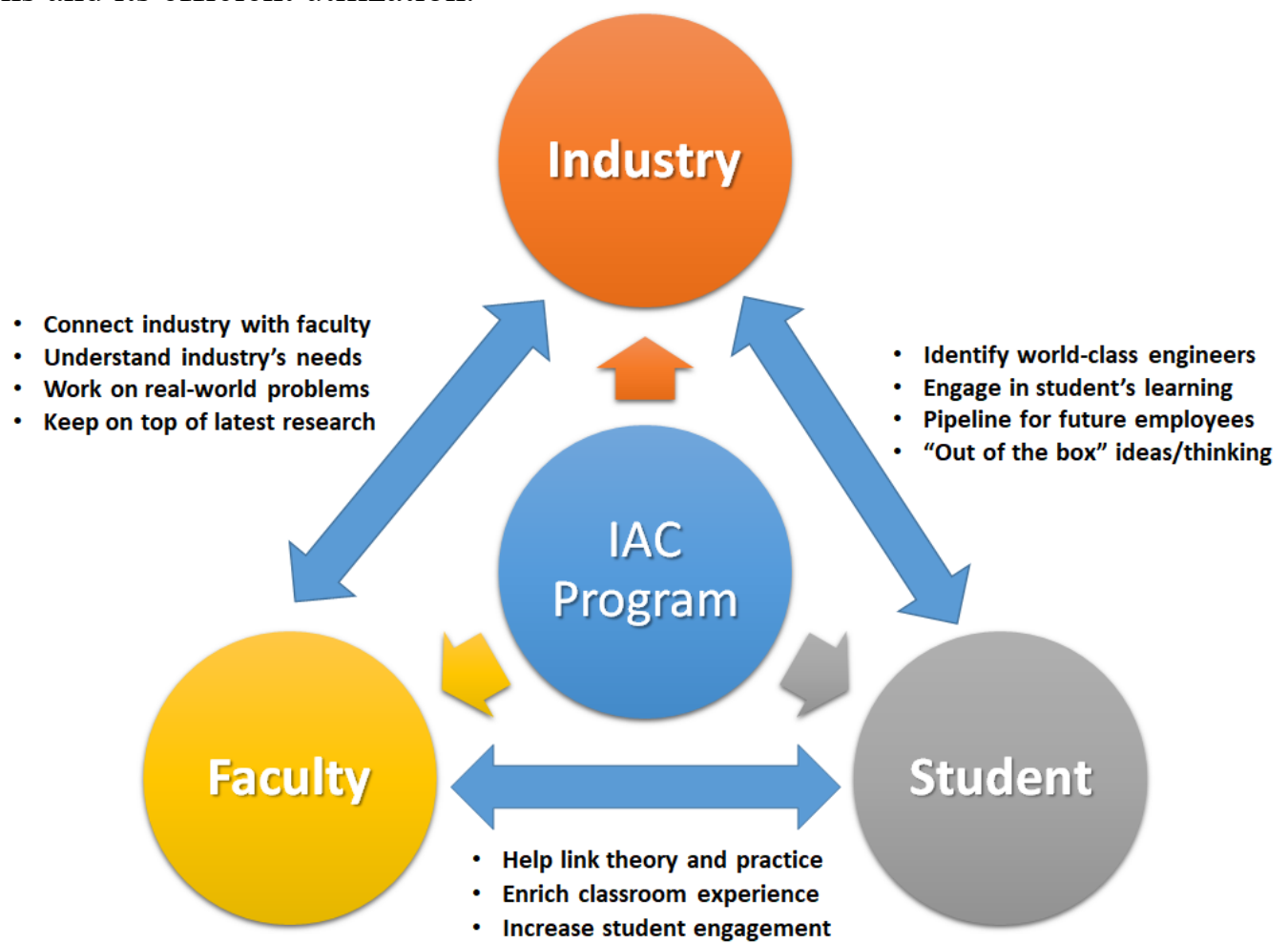

Figure 4: Benefits of IAC program for faculty, industry and students [10]. 
The environmental benefits are not only limited to reduction in greenhouse gases, the open source of database on energy-saving measures provides input to future energy-economic modeling efforts in climate related policy making. Finally, compliance with the DOE's requirements includes participating in best plant practices, fulfilling the goals of conducting 22 energy audits, submitting reports in a timely manner, and meeting other requirements that are communicated to the IAC.

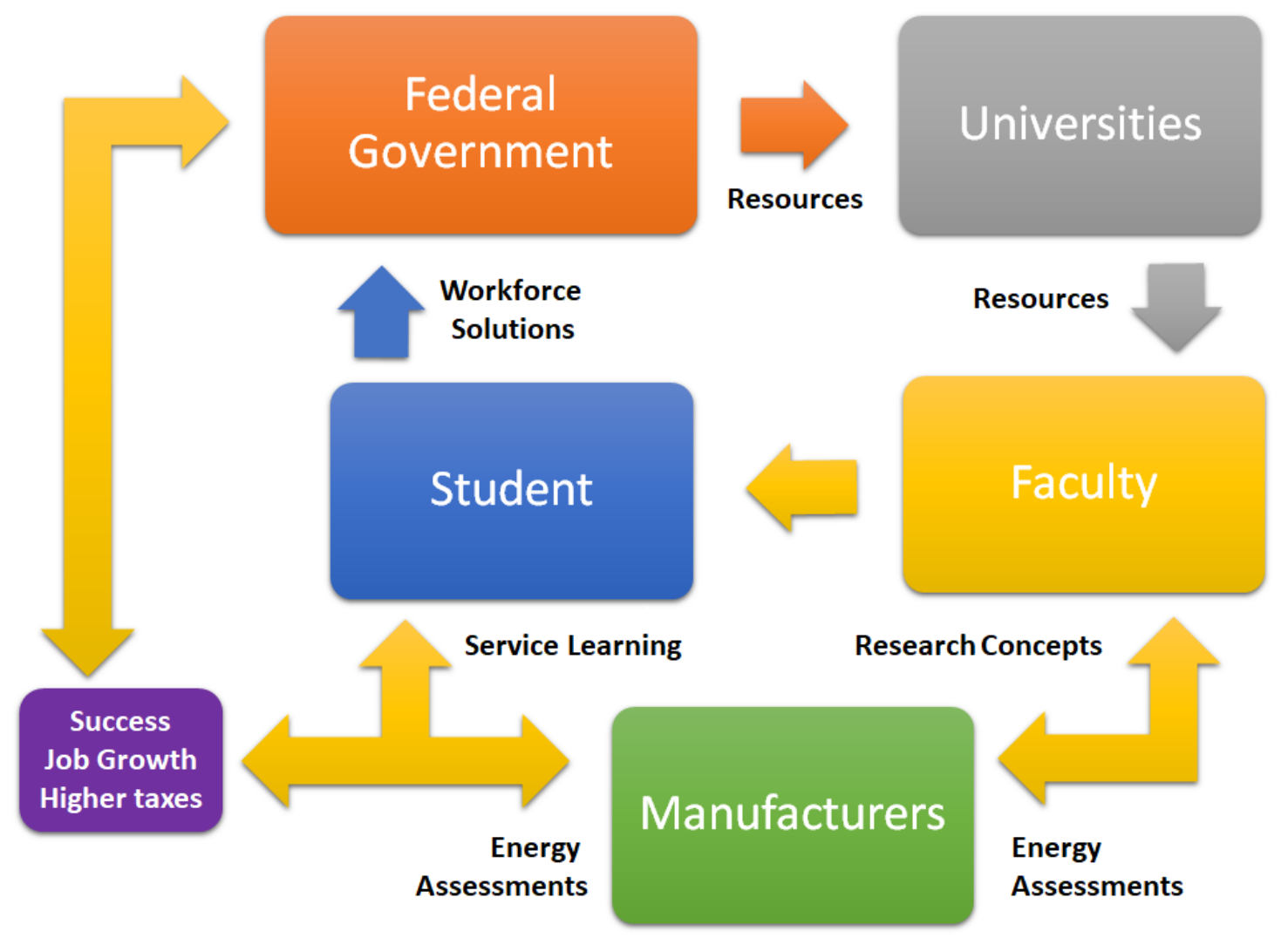

Figure 5: Benefits of IAC program for federal government [10].

\subsection{Professional development activities}

IAC provides opportunities for personnel development in students that have direct and indirect support to manufacturing plants. These include participating in the decision-making aids for industries, doing research on energy-related problems, conducting workshops, speaking at seminars. Students participate in every aspects of program that brings fascinations and challenges of energy engineering to the attention of student. Students with IAC activities are the first choice of employer to be hired in energy engineering career.

OSU offers academic curriculum through MET/IEM 4953/5953 to train students in applying energy engineering principles through energy audits. The course introduces students to industrial assessments, primarily energy, quality, and productivity-management. In addition to training and classes, the IAC also spreads awareness about the program and provide the students with leadership skills in promoting energy efficiency among the OSU students. IAC students are also 
involved in establishing two separate student chapters at OSU, namely (i) Society of Manufacturing Engineers (SME), and (ii) Association of Energy Engineers (AEE). The objective of SME is to educate students on manufacturing technology, manufacturing processes, and allow students to network. Similarly, the purpose of AEE is to promote the scientific and educational interests of those engaged in the energy industry and to foster action for sustainable development. The above-mentioned student organization in coordination with its national organizations conduct guest speaker presentations and spread awareness about manufacturing and energy industry. The goal of starting organizations like these is to reach out to students interested in manufacturing and energy and provide them with resources to grow and become knowledgeable in these fields through workshops, student discussions etc.

OSU-IAC students also get an outreach opportunity to attend various conferences where they get to network with industries professionals and learn about prospects industry trends. Recently in 2019 and 2020, the OSU-IAC has been represented in several state level manufacturing/ energy summits:

- Oklahoma Manufacturing Summit, Broken Arrow, OK

- Oklahoma Association of Energy Engineers (AEEOK) Trade Show, Owasso, OK

- Oklahoma Association of Energy Engineers (AEEOK) Conference, Owasso, OK

- 2020 Envision the future, AEEOK/OREC Roger Farrer Annual Energy Conference, Oklahoma City, OK

Also, AEEOK student chapter hosted following events:

- Lunch-n-learn event, AEEOK OSU Student Chapter Mentor Workshop: "Battery Afterlife at Spiers New Technology and EV Marketplace," August 28th, 2019. Speaker Kylah McNabb, Director of Business Innovation for Spiers New Technologies. Sponsored by AEEOK.

- Lunch-n-learn event, "Learn with Students! @ The OSU Industrial Assessment Center," August 29th, 2018. Speaker - Mr. Anthony Piguet, Sales manager for Atlas Copco Compressors. Sponsored by AEEOK.

At all these conferences/summits, IAC students have participated and presented about the IAC and made connections in the Energy/Manufacturing industry. Through the organizations like AEE and SME, OSU IAC helps to bridge the gap between students and professionals to work together for better future and overall energy management. The AEEOK had organized various events and seminars on campus so that the students get the chance to interact with professionals and thereby build themselves. Society of Manufacturing Engineers (SME) also offers students an opportunity to conduct various activities, conduct training and seminars through manufacturing professionals. Working closely with manufacturing professionals, companies, educators, schools and communities, SME shares knowledge and resources that generate solutions to manufacturing industry challenges.

\subsection{OSU IAC achievements}

The OSU IAC has been continuously operational for 38 years, as a reliable service-learning resource within the College of Engineering. Figure 6 shows the major milestones of this program across its four-decade history. 


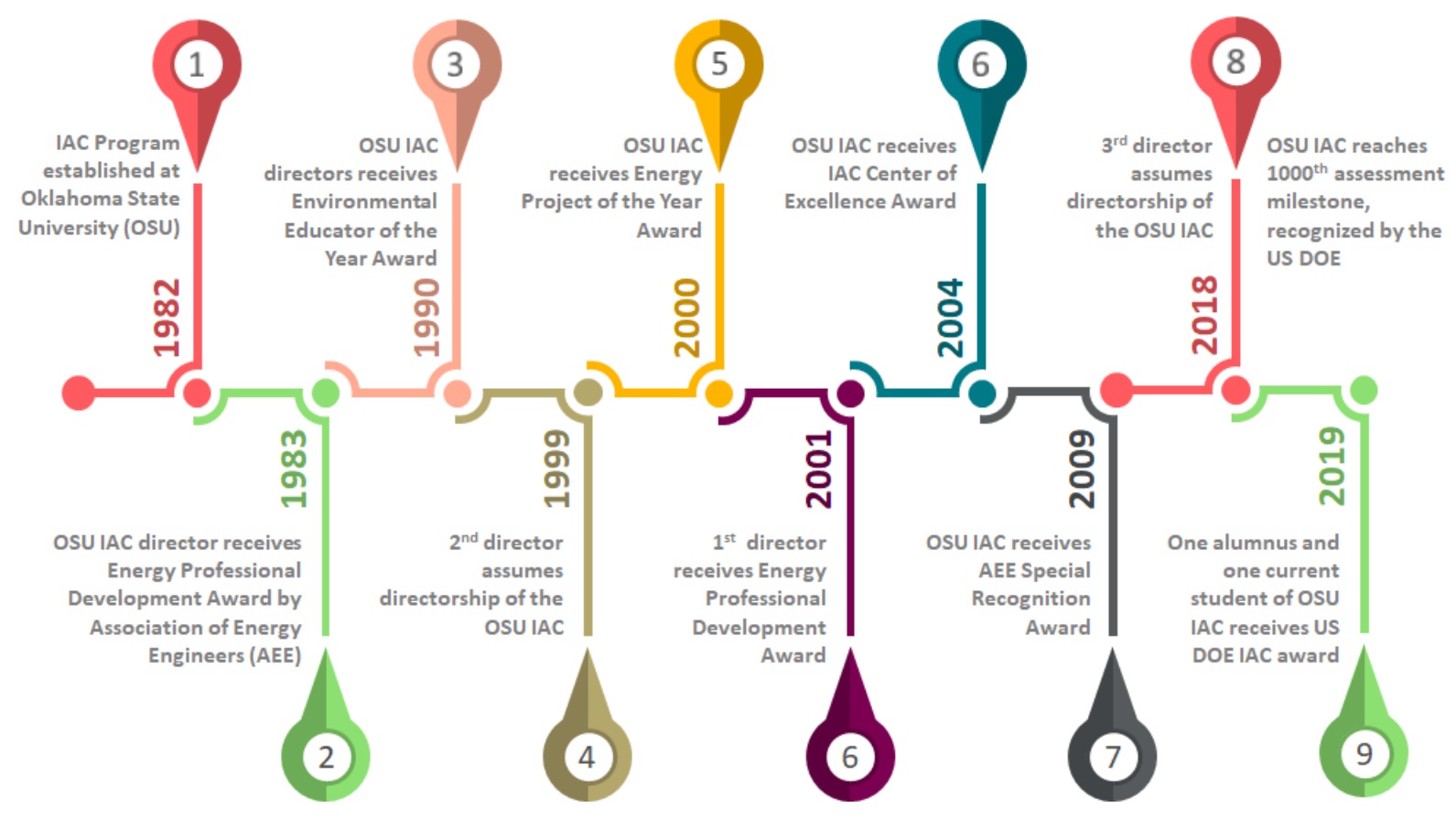

Figure 6: IAC program milestones since 1982.

The OSU IAC is one of the oldest service sites in this national program, continuously serving industry in the south plains since 1982. It is also the first center to reach the $1000^{\text {th }}$ assessment milestone among the 31 IACs nationwide. It has received the IAC Center of Excellence Award in the year 2004. Many of the OSU IAC alumni have made significant contributions in the Association of Energy Engineers (AEE) and have been awarded several prestigious awards such as 1983 Energy Professional Development Award, 1990 Environmental Educator of the Year Award, 2000 International Energy Project of the Year Award, 2001 Energy Professional Development Award, 2009 AEE Special Recognition Award, etc.

Two of the OSU IAC alumni have served as national president of the Association of Energy Engineers (AEE). Some of them have been recognized with Energy Managers Hall of Fame of AEE as well as Hall of Fame of the OSU College of Engineering, Architecture, and Technology. In addition, OSU IAC alumni have served as journal editors of several national and international journals such as Energy Engineering, Distributed Generation and Alternative Energy Journal, Strategic Planning for Energy and the Environment, Cogeneration and Distributed Generation Journal, etc.

Recently in 2019, an OSU IAC alumnus received the 2019 IAC Alumni Award for his/her contribution for outstanding accomplishments in promoting the practices, principles, and procedures of energy engineering in a professional or academic capacity after their IAC experience. In addition, one current OSU IAC employee received the 2019 IAC Student Award for outstanding accomplishments in promoting the practices, principles, and procedures in energy efficiency, productivity improvement and smart manufacturing, waste reduction, water conservation, energy management, and cybersecurity. 


\section{Results and discussion}

\subsection{Data and discussion about how the OSU IAC benefits the community}

IAC at OSU has provided 1,005 no-cost energy assessments at the facilities until the 2018-2019 cycle. It has produced 7,163 author recommendations with an average of 7.14 AR's per client, thus exceeding the organizational average of 4 . Of the 7,163 recommendations provided to the client 3,262 recommendations have been implemented. A total of 14 million MMBtu of energy savings were recommended as a result of energy efficiency measures resulting in $\$ 127.5$ million cost savings. Table 1 shows the top ten most commonly implemented energy-saving recommendations provided by IAC OSU in manufacturing industries:

Table 1: Top Ten Assessment Recommendations from OSU IAC*

\begin{tabular}{|c|c|c|c|c|}
\hline $\begin{array}{c}\text { Top ten energy saving } \\
\text { recommendations }\end{array}$ & Frequency & $\begin{array}{c}\text { Average } \\
\text { savings }\end{array}$ & $\begin{array}{c}\text { Average } \\
\text { payback }\end{array}$ & $\begin{array}{c}\text { Implementation } \\
\text { rate }\end{array}$ \\
\hline Condition smallest space necessary & 5 & $\$ 3,956$ & 1.3 & $100 \%$ \\
\hline $\begin{array}{c}\text { Increase amount of waste recovered } \\
\text { for resale }\end{array}$ & 11 & $\$ 5,077$ & 0.5 & $100 \%$ \\
\hline Pay bills on time to avoid late fees & 12 & $\$ 3,694$ & 0 & $88.9 \%$ \\
\hline Pay utility bills on time & 8 & $\$ 4,729$ & 0 & $85.7 \%$ \\
\hline $\begin{array}{c}\text { Adjust burners for efficient } \\
\text { operation }\end{array}$ & 5 & $\$ 37,735$ & 0.3 & $80 \%$ \\
\hline $\begin{array}{c}\text { Repair furnaces and oven doors so } \\
\text { that they seal efficiently }\end{array}$ & 5 & $\$ 2,684$ & 0.4 & $80 \%$ \\
\hline $\begin{array}{c}\text { Eliminate leaks in inert gas and } \\
\text { compressed air lines/valves }\end{array}$ & 496 & $\$ 3,941$ & 0.4 & $79.5 \%$ \\
\hline Repair and eliminate steam leaks & 38 & $\$ 14,941$ & 0.3 & $79 \%$ \\
\hline $\begin{array}{c}\text { Clean and maintain refrigeration } \\
\text { condensers and towers }\end{array}$ & 77 & $\$ 3,429$ & 0.7 & $76.4 \%$ \\
\hline $\begin{array}{c}\text { Establish burner maintenance } \\
\text { schedule for boilers }\end{array}$ & 12 & $\$ 31,981$ & 0.9 & $72.7 \%$ \\
\hline
\end{tabular}

* Data extracted from IAC database [12]

The most commonly-implemented recommendations above enjoy this status because they usually require little or no capital outlay, and they return their investment within one year in nine-out-of-ten cases. Also, the implementation of these suggestions normally does not disrupt the production process at a factory, which is a major consideration for plant managers. Moreover, the work required for uptake in these cases can usually be done using on-site maintenance staff with minimal risk of employee injury, if normal due diligence is exercised. The societal benefit of widespread industrial adoption of these simple measures includes reduced emissions from thermal power plants, improved air quality, and reduced reliance on importation of foreign fuel, which enhances American energy security.

The impact the OSU IAC in its region is evident through these numbers and will continue as energy auditing awareness increases and more students are trained. The OSU IAC strives to 
improve the economic condition of not only the state of Oklahoma but that of the neighboring states as well. Clearly, an IAC audit from OSU will yield results as students are introduced to the problems industries are facing and are given the opportunity to bring their fresh ideas and perspective towards solving them. OSU being a land-grant university, IAC has helped to achieve distinguished success in every research field possible by training the students and thus making the future generation of Oklahoma more advanced towards sustainable future through energy efficient technology.

\subsection{Data and discussion of how OSU IAC trains its students to excel in the workforce}

As of 2019, 216 students were supported through IAC program at OSU among which 67 students have received IAC Student Certificate from US DOE. Figure 7 shows the statistics of new students, active students, departing students and students with IAC certificates. The primary reason for the notable reduction in new and active students since 2013 has been the imposition of much reduced flexibility in hiring students, as mandated by the OSU Graduate College. For example, before 2013 , the director could hire graduate students at $1 / 8,1 / 4$, or $1 / 2$ time under the research assistant (RA) guidelines, but since then, all graduate students with RA contracts must be hired at half time---or not at all. This reduced flexibility has made it more difficult to fill the staff.

IAC Alumni graduate with an average of 8.9 specific skills applicable in the energy efficiency field. Alumni are hired almost twice as fast as their peers into an energy efficiency position. Many of IAC OSU alumni have been hired in companies such as Pepco Energy Services, EMCOR Group, Siemens, GE, and more. Others have gone on to work overseas in countries including Russia, China, and India. Some of our alumni have chosen to become educators at schools, such as OSU and University of Illinois Urbana-Champaign to pass on their knowledge.

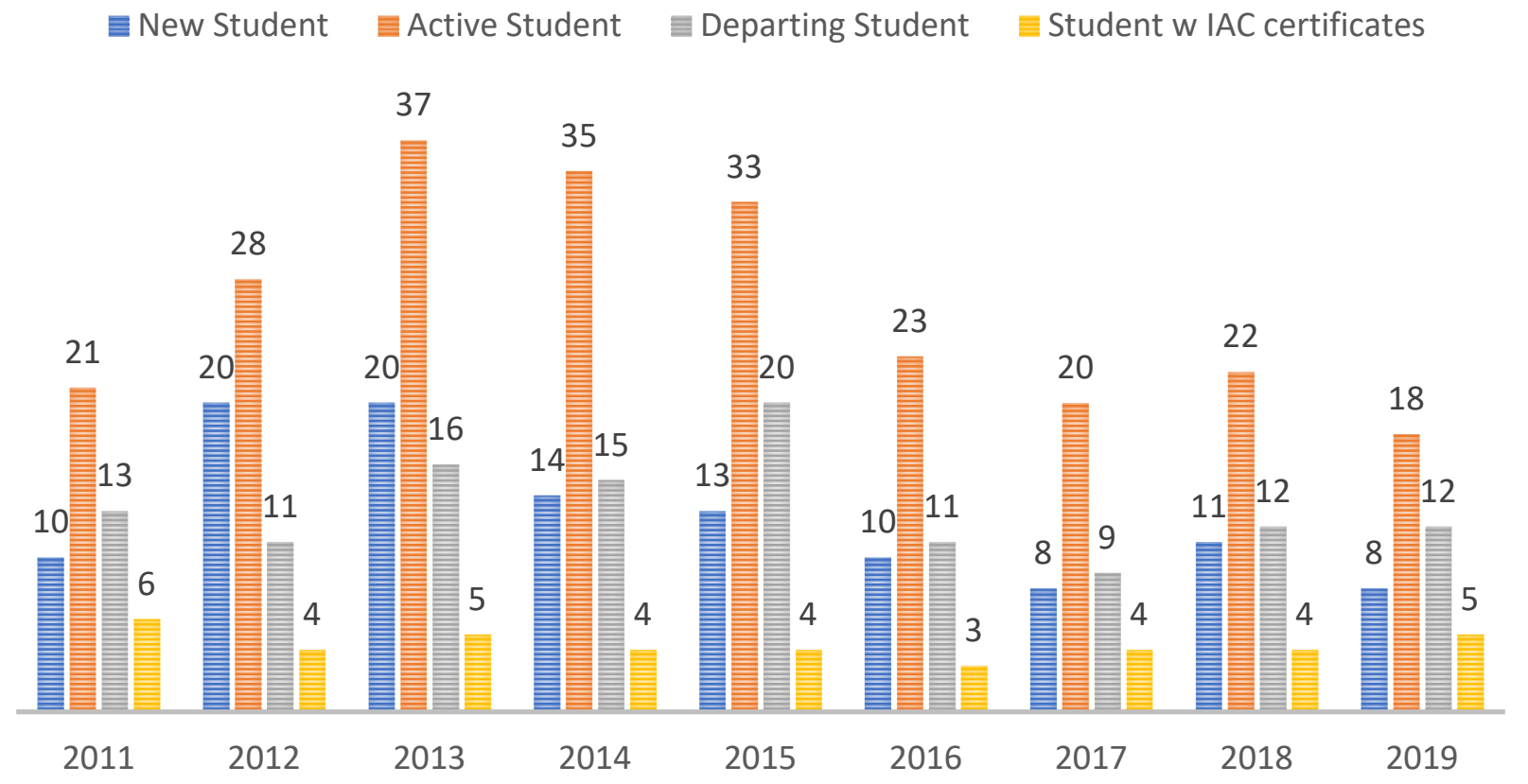

Figure 7: IAC-OSU Student Statistics (2011-2019) 
The OSU IAC trains students through a combination of classroom work, individual mentoring, and on-the-job training. Many of these students are expected to earn student certificates from the Department of Energy. The students' training focuses on energy conservation technologies in conjunction with increased productivity, economics of the same, and client relationships.

The IAC program has been training students to provide annual dollar savings through assessment recommendations. The trend of annual energy savings resulting in annual dollar savings (identified but not implemented) has been increasing constantly over the years. Figure 8 shows the increasing trend of annual dollar savings from the year 2010 to 2019. While the annual increase may not look impressive, one must keep in mind that, as industrial managers implement the easier and shorter-payback energy-saving measures, it becomes increasingly challenging for our students to identify new, viable energy-saving ideas. At the current time, we often visit plants in which the "low-hanging fruit" has already been picked. For example, roughly half of the plants that we have assessed in the past 12 months have already retrofitted their lighting systems with state-of-the-art LED energy-saving fixtures.

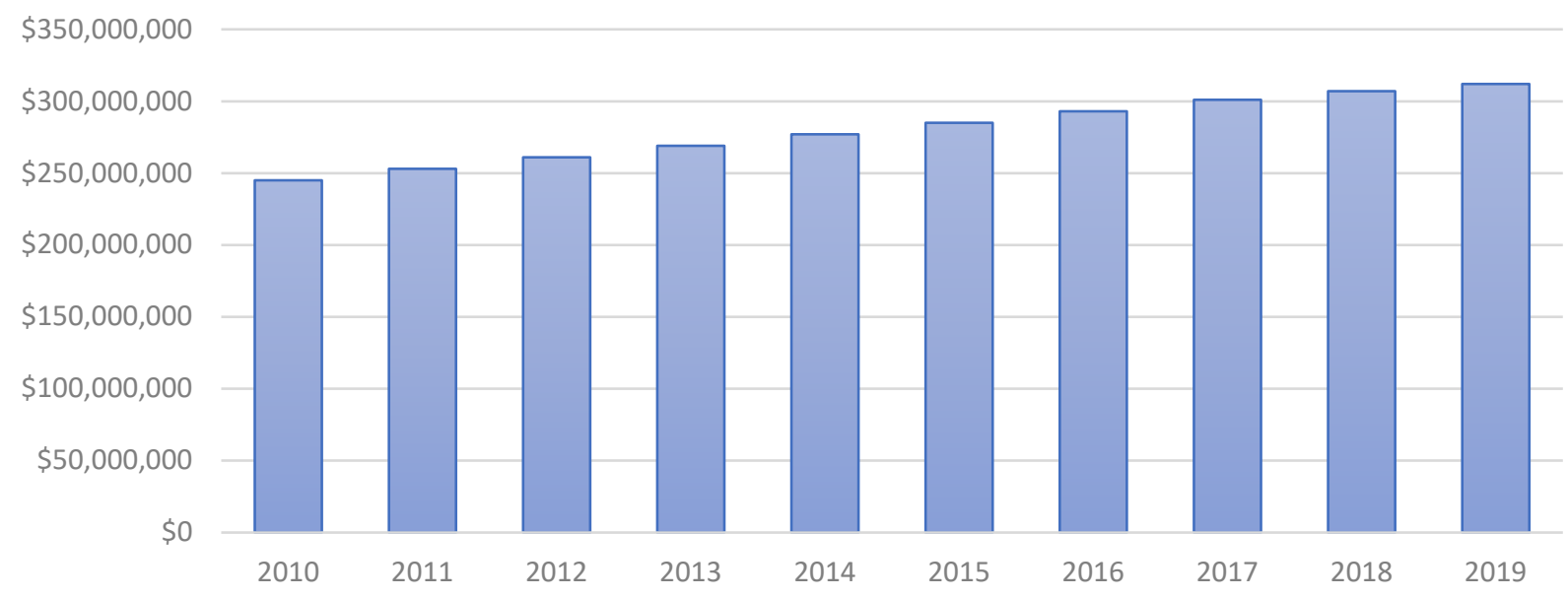

Figure 8: IAC-OSU Yearly Dollar Savings Statistics

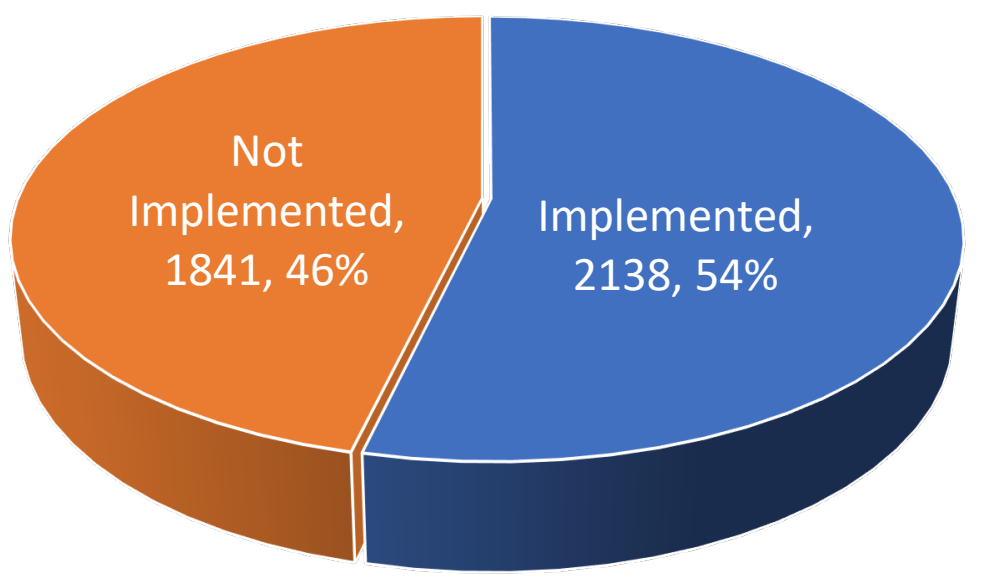

Figure 9: Assessment Recommendation Implementation Status 
Figure 9 shows the implementation status of IAC energy conservation recommendations. Looking at the data of 10-year period between 2006-2016, 54\% of recommendations has been implemented. The recommendations provided by students having $54 \%$ implementation rate is a big accomplishment which makes them a good fit and grow faster in their professional careers. The approximately $46 \%$ of recommendations that are not implemented are associated with projects that require significant capital investment and longer payback periods (typically three years or more). These measures are contrasted with the often-cited "low-hanging fruit" in the energy auditing community, referring to measures that pay back in less than two years and that require little or no capital investment.

Since the year 1900, the world's collective energy consumption has been increasing at a rapid rate, except for temporary disruptions caused by wars, economic recessions, and disease pandemics. The U.S. Energy Information Administration (EIA) projects that the use of energy will grow approximately 50\% between 2018 and 2050 [13]. Such heavy use of energy has created concern about global climate change. Some effects such as shrinking glaciers, accelerated sea level rise, intense heat waves, and loss of sea ice have already been observed [14]. The reduction of greenhouse gases can play a major mitigating role in coping with these adverse impacts. In this context, the IAC program at OSU in its four decades of service has helped to displace 1.91 million metric tons of carbon dioxide emissions from industrial sources. Figure 10 shows the increasing trend of $\mathrm{CO}_{2}$ savings (in this program) in million metric tons from the year 2010 to 2019.

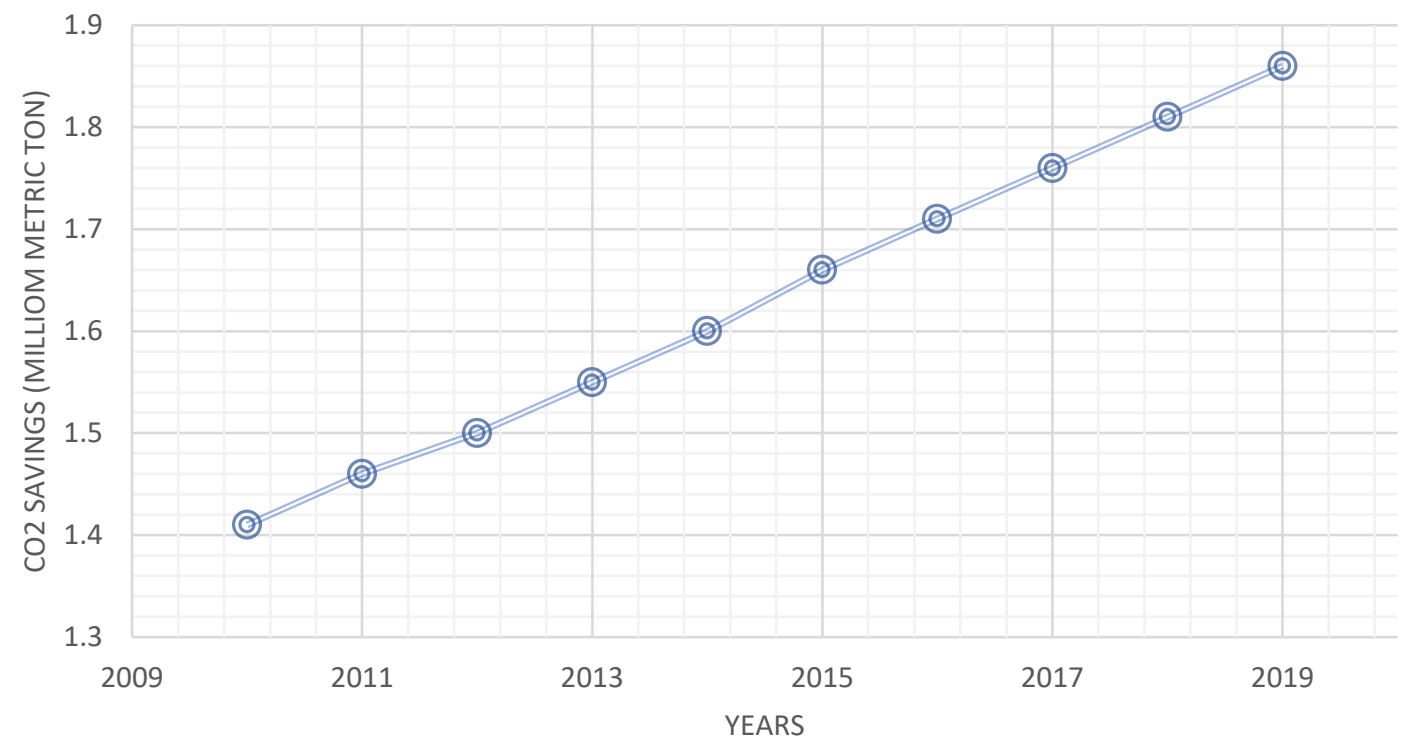

Figure 10: $\mathrm{CO}_{2}$ savings in million metric tons (2010-2019)

These beneficial emission reductions associated with the field activity of the OSU IAC are primarily due to the diligent efforts of the student employees. These emission reductions are especially important in that the majority of all electricity in our four-state OSU-IAC service territory is generated by thermal power plants burning either coal or natural gas. In contrast, some IAC offices are located in regions in which the bulk of electricity is generated by hydroelectric plants (which have virtually no emissions), such as the IAC at Oregon State 
University. The de-facto $\mathrm{CO}_{2}$ savings resulting from the Oregon team's assessments are far lower than those generated by the Oklahoma State IAC. Figure 11 illustrates a map of all the assessments performed by OSU from 1982 to 2019.

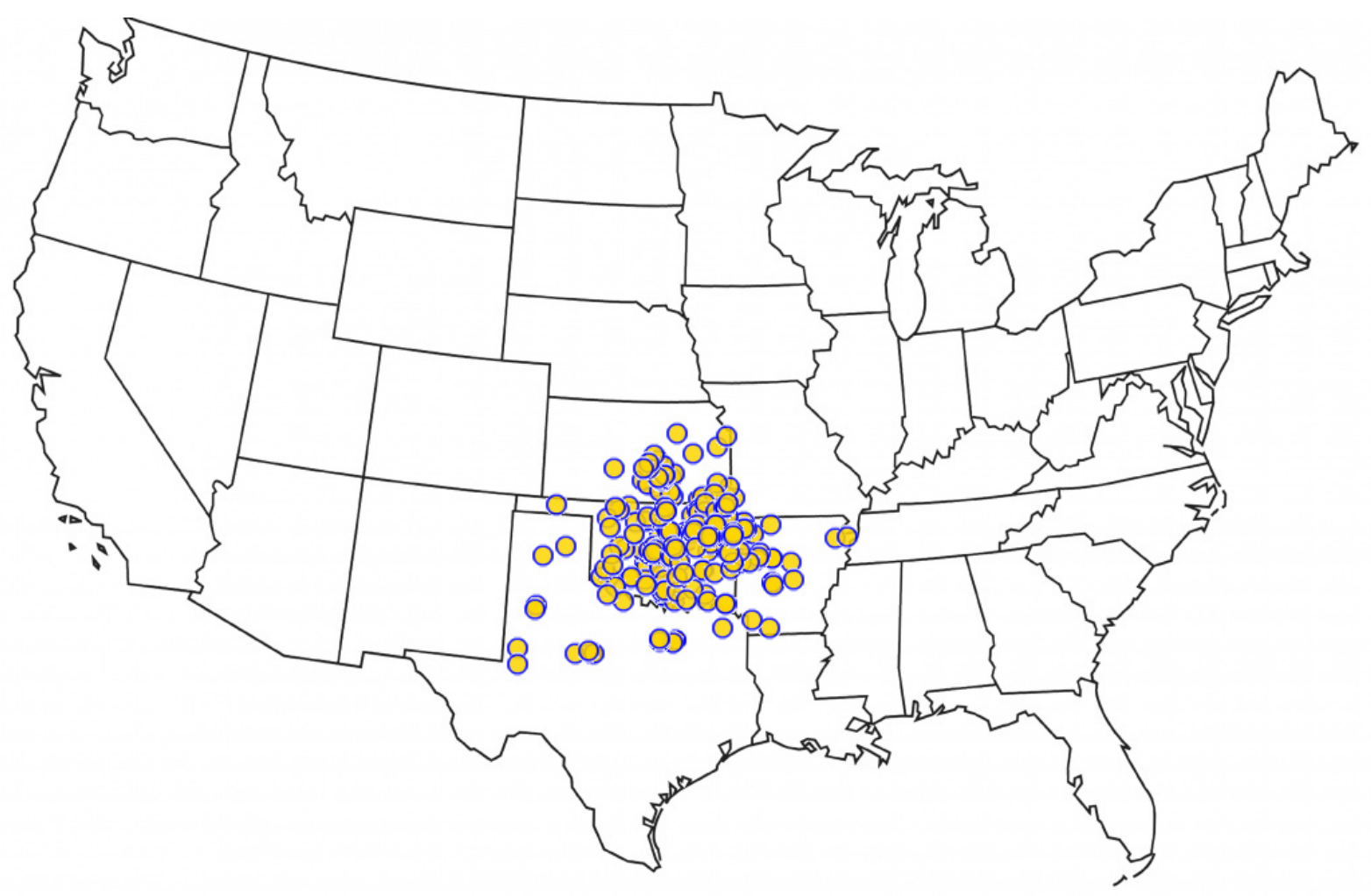

Figure 11: Map of assessments completed by the OSU-IAC as of 2019 [1]

Every year the OSU IAC tries to expand its clientele by participating in various conferences around the region. The Oklahoma Manufacturing Summit and OSU IAC have formed an important and strong partnership to foster the region's economic growth and promote the best industry practices. The way the IAC provides these recommendations to its clients for no charge and the way they can produce results of high caliber is truly remarkable. It established a wellknown brand around the manufacturing consensus of Oklahoma as it tries to expand its influence and impact into other regions. Table 2 is another which shows the impact the OSU IAC has on its neighboring states.

Table 2. Assessments performed by the OSU IAC from 1982 through 2019

\begin{tabular}{|c|c|c|c|c|c|c|}
\hline State & Assessments & Recommendations & $\begin{array}{c}\text { Recommended } \\
\text { Savings }\end{array}$ & $\begin{array}{c}\text { Implemented } \\
\text { Recommen- } \\
\text { dations }\end{array}$ & $\begin{array}{c}\text { Implemented } \\
\text { Savings }\end{array}$ & $\begin{array}{c}\text { Implemen- } \\
\text { tation Rate }\end{array}$ \\
\hline AR & 98 & 676 & $\$ 14,299,874$ & 320 & $\$ 4,350,129$ & $49.9 \%$ \\
\hline KS & 107 & 855 & $\$ 13,069,230$ & 361 & $\$ 4,043,540$ & $43.9 \%$ \\
\hline MO & 5 & 40 & $\$ 1,612,693$ & 24 & $\$ 1,449,120$ & $60 \%$ \\
\hline OK & 770 & 5,352 & $\$ 93,383,240$ & 2,482 & $\$ 22,585,023$ & $48.1 \%$ \\
\hline TX & 22 & 237 & $\$ 5,064,052$ & 97 & $\$ 904,515$ & $40.9 \%$ \\
\hline
\end{tabular}


The implementation rate of the assessment recommendations averages out to be $48.56 \%$. One of the main reasons for this lower implementation may be high payback period or high investment cost. The implementation of assessment recommendations mostly depends on the projects with shorter payback, lower implementation cost and greater annual savings, as explained by Anderson and Newell [15], Muthulingam et al. [16] and Abadie et.al. [17]. In the year 2019, the OSU IAC saved 30.46 TBtu of energy. Figure 12 displays the energy saved in TBtu for the past ten years.

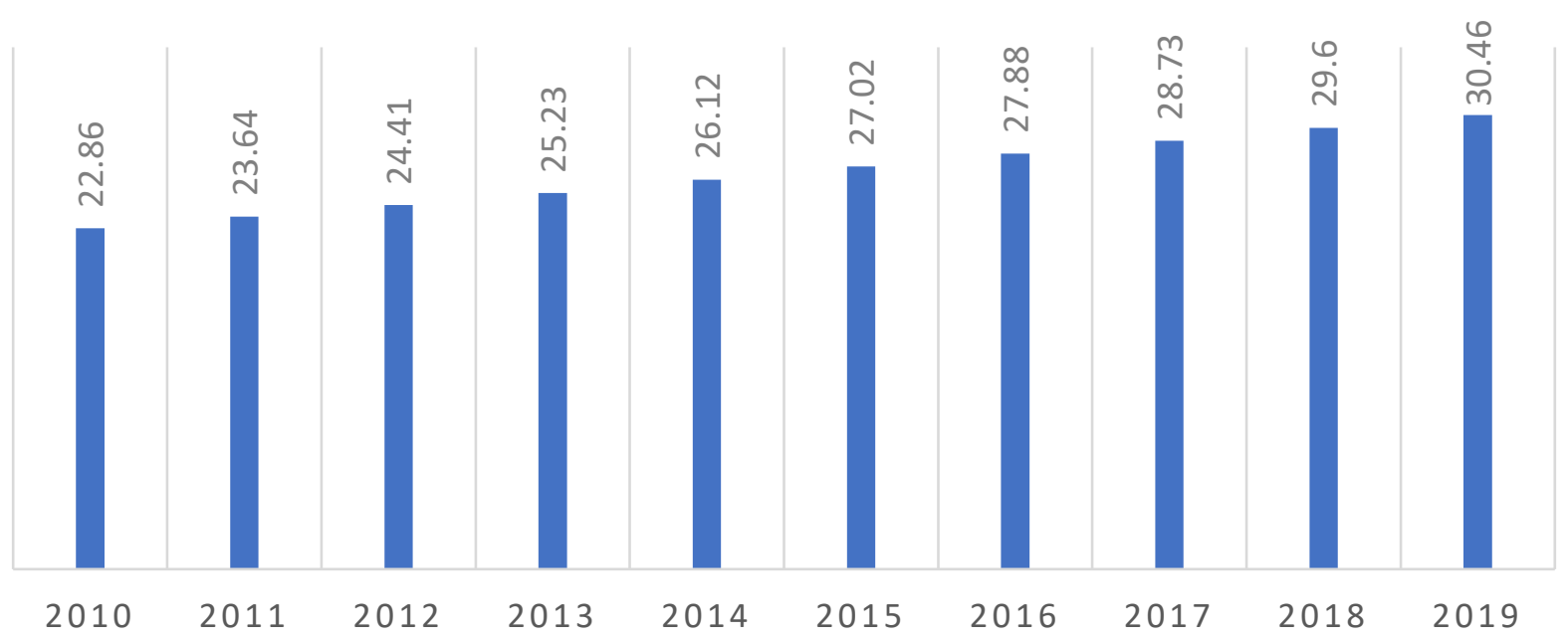

Figure 12: Energy saved in TBtu from 2010 through 2019.

The results overall show an increasing trend of annual energy and cost savings ranging from \$245 million to \$312 million in a ten-year time frame, along with the 1.91 million metric tons of $\mathrm{CO}_{2}$ emission reduction by the year 2019 , and the cumulative energy savings of 30.46 trillion Btu by 2019 . Based on the presented data, it is evident that the OSU IAC has made a positive impact not only on the students and manufacturers but also on society at large, by reducing industrial greenhouse gas emissions.

\section{Conclusion}

The Industrial Assessment Center at Oklahoma State University is an integral part of this state's agricultural and mechanical university. It trains its students, fosters economic vitality in its 200,000 square-mile service territory, and conducts practical, field-based research - thereby helping the university to fulfill its Land-Grant mission. The mission of the IAC is very much in alignment with the founding charter of OSU, and this is evident in the data and description heretofore presented. In the final analysis, we argue that the IAC program is a shining example of a government-funded service-learning initiative that should be adopted by governments world-wide, to train the next generation of energy and environmental engineers.

\section{Acknowledgement}

The authors wish to thank the Advanced Manufacturing Office within the US Department of Energy for providing financial support to the Industrial Assessment Center at Oklahoma State University (DOE Grant \# EE000719). This article was prepared as an account of work sponsored 
by an agency of the United States Government. However, neither the United States Government nor any agency thereof, nor any of its employees, makes any warranty, expressed or implied, or assumes any legal responsibility for the accuracy, completeness, or usefulness of any information included in this article. Reference herein to any specific commercial product, process, or service by trade name, trademark, manufacturer, or otherwise does not necessarily constitute or imply its endorsement by the United States Government or any agency thereof. The views and opinions of authors expressed herein do not necessarily reflect those of the United States Government or any agency thereof.

\section{References}

[1] Industrial Assessment Center. Available from https://iac.university/

[2] US Department of Energy (1996). “Analysis of Energy-Efficiency Investment Decision by Small and Medium-Sized Manufacturers.” DOE/PO-0043. Washington, DC.

[3] Oklahoma State University. Available from https://iac.okstate.edu/

[4] Chappell, C. (1991) Research Centennial Histories Series, Stillwater, OK: Oklahoma State University

[5] Oklahoma State University. Available from http://timeline.okstate.edu/?event=2844

[6] History and overview of the land grant college system. Available from https://www.nap.edu/read/4980/chapter/2

[7] The Library of Congress. Available from

https://www.loc.gov/rr/program/bib/ourdocs/morrill.html

[8] Industrial Assessment Center Newsletter (2019). Available from:

https://www.energy.gov/sites/prod/files/2019/06/f64/IAC_newsletter_Summer2019.pdf

[9] (2019) Full Issue PDF Volume 116, Issue 3, Energy Engineering, 116:3, 1-80, DOI:

$10.1080 / 01998595.2019 .12057056$

[10] Gopalakrishnan, B., Nimbalkar, S. U., Wenning, T. J., \& Thirumaran, K. (2017). Industrial Assessment Center (IAC) Operations Manual (No. ORNL/TM-2016/676). Oak Ridge National Lab. (ORNL), Oak Ridge, TN (United States).

[11] Society of Manufacturing Engineers. Available from: https://www.smeef.org/about$\underline{\text { smeef/who-we-are/ }}$

[12] Industrial Assessment Center. Available from

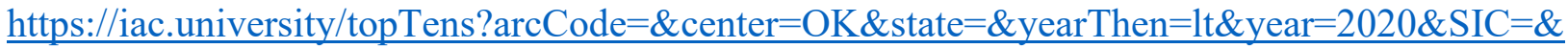
$\underline{\text { NAICS }=\& \text { showTop }=10 \& \text { sortBy }=\text { impRate } \& \min R \text { equired }=5}$ 
[13] International Energy Outlook 2019, Available from https://www.eia.gov/outlooks/ieo/pdf/ieo2019.pdf Accessed 7 January 2020

[14] Global Climate Change, NASA, Available from: https://climate.nasa.gov/effects/Accessed $01 / 07 / 2020$

[15] Anderson, S. T., \& Newell, R. G. (2004). Information programs for technology adoption: the case of energy-efficiency audits. Resource and Energy Economics, 26(1), 27-50.

[16] Muthulingam, S., Corbett, C. J., Benartzi, S., \& Oppenheim, B. (2009). Managerial biases and energy savings: An empirical analysis of the adoption of process improvement recommendations. Working Paper UCLA Anderson School of Management.

[17] Abadie, L. M., Ortiz, R. A., \& Galarraga, I. (2012). Determinants of energy efficiency investments in the US. Energy Policy, 45, 551-566.

[18] US Federal Trade Commission, Bureau of Consumer Protection - Division of Enforcement. https://www.ftc.gov/sites/default/files/attachments/press-releases/ftc-warns-replacementwindow-marketers-review-marketing-materials-energy-savings-claims-mustbe/120829windowsnewproletter.pdf Accessed 19 March 2020.

[19] Industrial Assessment Center. (2020, April 24). Sample of Assessment Report of IAC at Oklahoma State University. https://iac.okstate.edu/sites/default/files/Sample\%20\%200SU\%20IAC\%20Assessment\%20Report.pdf Accessed 24 April 2020. 